ORIGINAL RESEARCH PAPER

\title{
IMPACT OF THE EXTRACTION METHOD ON PHYSICO-CHEMICAL PROPRIETIES, PHYTOCHEMICALS AND BIOLOGICAL ACTIVITY OF SESAME SEEDS OIL
}

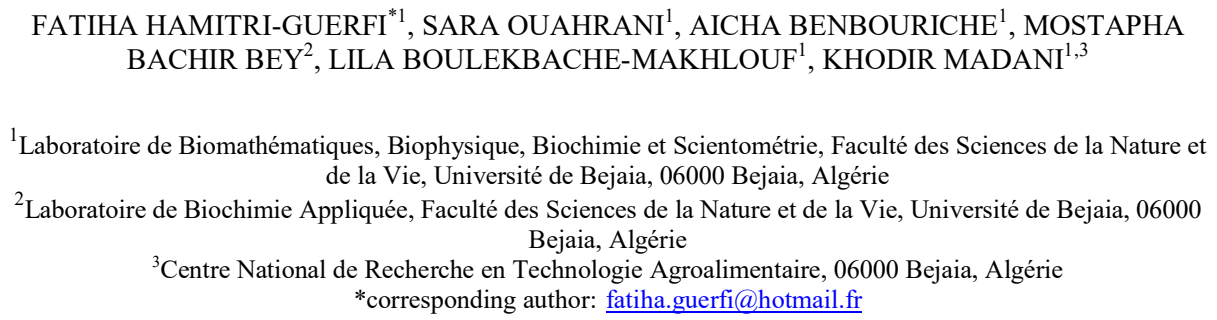

${ }^{1}$ Laboratoire de Biomathématiques, Biophysique, Biochimie et Scientométrie, Faculté des Sciences de la Nature et de la Vie, Université de Bejaia, 06000 Bejaia, Algérie

${ }^{2}$ Laboratoire de Biochimie Appliquée, Faculté des Sciences de la Nature et de la Vie, Université de Bejaia, 06000 Bejaia, Algérie

${ }^{3}$ Centre National de Recherche en Technologie Agroalimentaire, 06000 Bejaia, Algérie

*corresponding author: fatiha.guerfi@hotmail.fr

Received on 18 October 2019

Revised on 18 May 2020

\begin{abstract}
This study aimed at characterizing oil extracted from roasted and unroasted sesame seeds (Sesamum indicum L.) following either Soxhlet using hexane as the solvent or cold pressing. We obtained an inverse relationship between oil yield and seed moisture content. Seed roasting as well as Soxhlet extraction improved oil yield. Specific absorptivity (at 232 and $270 \mathrm{~nm}$ ) increased with heating treatment. Refractive values of the different oils were about 1.464. Peroxide value was 7.6 to $9.6 \mathrm{meq} \mathrm{O}_{2} / \mathrm{kg}$, iodine value was $107-109 \mathrm{~g} \mathrm{I}_{2} / 100 \mathrm{~g}$, saponification value obtained was 188 to $190 \mathrm{mg} \mathrm{KOH} / \mathrm{g}$, oleic and linoleic acids were about 42 and $40 \%$, respectively. Total phenolic contents were 8 (USO-CE) to $17 \mathrm{mg} / 100 \mathrm{ml}$ (RSO-SE). Roasting process increased the antioxidant contents and activities (DPPH scavenging and reducing power). The antibacterial activity of sesame oil revealed the inhibition of Escherichia coli and Pseudomonas aeruginosa growth. Sesame oil presents interesting physicochemical characteristics and antioxidant properties that can be improved by roasting the seeds before extraction.
\end{abstract}

Keywords: Sesame oil, roasting, antioxidants, antibacterial activity

\section{Introduction}

Epidemiological studies suggest that consumption of plant-based foods is beneficial to health and contributes to the prevention of degenerative processes, hence lowering the incidence and mortality rate from cancer, cardio, and cerebrovascular diseases (Halliwell, 1997).

https://doi.org/10.35219/foodtechnology.2020.1.05 
Among these plants, sesame seed (Sesamum indicum L.), which belongs to the Pedaliaceae family, cultivated in Asia and Africa especially in Sudan, Ethiopia and Nigeria (FAO, 2010) contain (50-60\%) lipids, (20-25\%) protein with an exceptionally high amount of methionine (2.5- $4.0 \%$ ), carbohydrates (1.6-1.8 \%) (Lyon, 1972), and about 4.5-9 \% of ash (Abou-Gharbia et al., 1997; Gharby et al., 2015).

Furthermore, sesame seeds are an excellent source of copper, calcium, phosphorus, iron, magnesium, manganese, zinc, and vitamin B1 (Nayar and Mehra, 1995; Anilakumar et al., 2010).

Sesame seeds oil serves as a source of edible vegetable oils including essential fatty acids belonging to both omega-3 and omega- 6 fatty acids. Acyl lipid classes of different Sesamum species were reported by Kamal-Eldin and Appelqvist (1994). The minor components as polyphenols belong to a variety of compounds which are often bioactive (Fukuda et al., 1985).

In Algeria, sesame seeds are consumed exclusively in its raw form where they are used in confectionery and as a topping for bread and rolls, whereas, in other countries, sesame is among the important oil yielding plants. The traditional way of extracting sesame oil is done in a wooden mortar the oil being removed by floating it with hot water. In Africa and India, the screw presses are widely used, the oil is pressed out by hydraulic process as well. At the present time, a combination of pressing and solvent extraction is employed for greater recovery of oil.

Several researchers were focused on finding an adequate extraction method, so different extraction methods, such as liquid-solid extraction, Soxhlet, sonication, and supercritical fluid extraction have been used to isolate oils from plant seeds (Rajaei et al., 2008; Warra, 2011; Döker et al., 2010). Recently, Junpeng et al. (2019) proposed a new extraction method using steam explosion technology.

Indeed, the quality of oil depends essentially on its chemical composition and that following the seeds treatment and conditions of extraction, the various constitutive elements can affect the quality of oil (Kandji, 2001).

In Middle Eastern countries, sesame seeds are often roasted prior to oil extraction because it is the key step for the development of its desirable color and flavor. Several studies assessed the quality and the efficiency of roasting under different conditions and according to different factors, noticing the relationship between the roasting conditions and the development of antioxidant activity which provides oxidative stability to sesame oil (Kim, 2000; Janat et al., 2010; Lee et al., 2010).

The aim of the present investigation was to study the effect of two extraction methods (Soxhlet and cold pressing) on chemical composition, antioxidant and antimicrobial activities of sesame oil from roasted and unroasted seeds.

\section{Material and methods}

\section{Sample preparation}

Twenty-one kilograms of sesame seeds (S. indicum L.), imported from India were purchased from local markets. For the sample preparation, the drying of sesame 
seeds was carried out using an oven (Binder FD 53, Netherlands) equipped with ventilation at $50^{\circ} \mathrm{C}$ until constant weight. The roasted fraction of seeds was treated at $180^{\circ} \mathrm{C}$ for $20 \mathrm{~min}$ (Hassan, 2013).

The samples (dried and roasted) used for Soxhlet oil extraction were milled with a coffee grinder (Bixuyao, China). The two fractions of sesame seeds destined for cold pressing extraction were milled using an industrial grounder.

\section{Extraction of oil}

Two methods were used for oil extraction, Soxhlet extraction, and cold pressing.

Soxhlet extraction: Thirty grams of sample were used for oil extraction with 250 $\mathrm{ml}$ of hexane during $5 \mathrm{~h}$. The solvent was removed from the extracted oil using a rotary evaporator (Buchi R-210, Switzerland) and residual solvent was excluded by oven at $50^{\circ} \mathrm{C}$ until constant weight (AOAC, 2005; NF EN ISO 659, 2009).

The extraction yield was calculated according to equation 1 .

$$
Y=\frac{W_{t}-W_{f}}{W_{s}} \times 100
$$

where $\mathrm{Y}$, extraction yield; $\mathrm{W}_{\mathrm{t}}$, weight of flask with oil; $\mathrm{W}_{\mathrm{f}}$, weight of the empty flask; $\mathrm{W}_{\mathrm{s}}$, weight of sample ( $30 \mathrm{~g}$ of sesame seeds powder).

Cold pressing Extraction: This is a common method in which sesame oil can be extracted under low temperature conditions without any chemical solvents (Warra, 2011).

The sesame seeds were milled and the oil was extracted using mechanical pressure. Oil was poured in glass bottles and protected against the light after they were transported to laboratory and stored at $4^{\circ} \mathrm{C}$.

The extraction yield was calculated with the following formula: $\mathrm{Y}=\left(\mathrm{W}_{\mathrm{o}} / \mathrm{W}_{\mathrm{s}}\right) * 100$

where: $\mathrm{W}_{\mathrm{o}}$, the weight of extracted oil; $\mathrm{W}_{\mathrm{s}}$, the weight of seeds sample $(10 \mathrm{~kg})$.

Physical and chemical analysis of extracted oil

Moisture determination of sesame seeds and oil: The moisture content $(\mathrm{H})$ was determined by drying samples ( 2 grams) powder or oil of sesame at $105^{\circ} \mathrm{C}$ until a constant weight was reached. Then the moisture content was calculated using equation 2 (AOAC, 2008):

$$
\mathrm{H}=\frac{W_{\text {initial }}-W_{d r y}}{W_{d r y}} \times 100
$$

where $\mathrm{H}$, moisture content; $\mathrm{W}_{\text {initial }}$, fresh weight; $\mathrm{W}_{\text {dry }}$, dry weight.

Color: The Lovibond (PX 880, UK) was used for color measurements, whereby the color of the raw material was compared against a series of colored standard glasses, under a standard light source. Once the sample was poured in the cell of Lovibond, the color was determined while comparing it with color standard blades. Reading was done by regulation of two faces; the observation was conducted until the obtaining of the same color for both sides, then, reading on the board values of the 
yellow and red. The results were expressed by the number of yellow and red units necessary to obtain the corresponding color (Sudke and Sakarkar, 2013).

\section{Specific absorptivity}

The conjugated dienes and trienes formation were measured spectrophotometrically at 230 and $270 \mathrm{~nm}$ respectively. About 0.1 grams of oil was accurately weighed dissolved in cyclohexane and transferred quantitatively to a 50 $\mathrm{ml}$ glass-stoppered volumetric flash (AOAC, 1997).

\section{Refractive Index determination}

The sample (10 grams) of oil was melted on a water bath at $40^{\circ} \mathrm{C}$ till a clear solution was obtained. Refractive index was determined at room temperature $\left(25^{\circ} \mathrm{C}\right)$ using a refractometer according to Mordret et al. (1997).

\section{Peroxide value}

Primary products of lipids oxidation (hydroperoxides, peroxides, and radical peroxyles) were the main compounds considered by this parameter. For this, 5 grams of oil were weighed and were subjected to iodometric determination of peroxide value according to AOCS official method.

\section{Iodine value}

Iodine value is the mass of iodine considered in grams that are consumed by 100 grams of oil. This parameter determines the amount of unsaturation in fatty acids; the higher the iodine value, the more double bonds are present in the fat. Iodine value was determined according to the micro-method of Kaufman (1958).

\section{Saponification Value}

Accurately 2 grams were weighed and boiled on a water bath for 30 minutes with $25 \mathrm{ml}$ of 0.5 methanolic potassium hydroxide. The mixture was titrated immediately with $0.5 \mathrm{~N}$ Hydrochloric acid solutions in the presence of phenolphthalein solution as colored indicator. This procedure was repeated for blank titration without sample. The saponification value was calculated using the following equation 3 (Sudke and Sakarkar, 2013).

$$
\mathrm{S} v=\frac{(V s-V o) * C_{H C l} * M W_{K O H}}{W}
$$

where: Sv, Saponification value; $\mathrm{V}_{\mathrm{s}}$, hydrochloric acid volume needed for sample; $\mathrm{V}_{0}$, hydrochloric acid volume needed for blank; $\mathrm{C}_{\mathrm{HCl}}$, hydrochloric acid concentration; $\mathrm{MW}_{\mathrm{KOH}}$, molar weight of $\mathrm{KOH}(56.10 \mathrm{~g} / \mathrm{mol})$; W, sample weight $(\mathrm{g})$.

\section{Fatty acid analysis of sesame oil}

Fatty acid methyl esters were prepared using a standard method (NF T 60-234: 1977) and applied by El Hachimi et al. (2015). Fatty acid composition of sesame oils was analyzed with a gas chromatography system (Chrompack $C$ 9002) equipped with an injector spraying to the temperature of $250^{\circ} \mathrm{C}$ and DB23 capillary column ( $30 \mathrm{~mm}$ length $\times 0.32 \mathrm{~mm}$ internal diameter, particles size $<0.25 \mu \mathrm{m}$ ). The temperature was programmed starting at a constant temperature of $130^{\circ} \mathrm{C}$ for one minute, and then increased to $170^{\circ} \mathrm{C}$ at a rate of $6.5^{\circ} \mathrm{C} / \mathrm{min}$, until $215^{\circ} \mathrm{C}$ with 
$6.5^{\circ} \mathrm{C} / \mathrm{min}$, and raised by using $40^{\circ} \mathrm{C} / \mathrm{min}$ for $3 \mathrm{~min}$. Hydrogen was used as a carrier gas, and the injector, oven and detector temperatures were $250^{\circ} \mathrm{C}$. The injected volume was $1 \mu \mathrm{l}$. Fatty acids were identified by comparison with relative retention times of standards and calculation of equivalent chain length values (Ichihara et al., 1996).

\section{Antioxidant compounds determination}

Antioxidants extraction: The extraction of antioxidant compounds from oils was performed as described by Gutfinger (1981). Ten grams of oil was dissolved in hexane $(20 \mathrm{ml})$ and the solution successively was subjected to extraction three times with $20 \mathrm{~mL}$ of $60 \%$ aqueous methanol. The mixture was shaken and the polar phase was recovered after centrifugation (4000 rpm/10 min).

Determination of Total Phenolic Content (TPC): The extraction of phenolic compounds was performed following Gutfinger (1981). TPC was determined by Folin-Ciocalteu colorimetric method (Singleton and Rossi, 1965). An aliquot of sesame oil extract $(0.5 \mathrm{ml})$ was mixed with $0.5 \mathrm{ml}$ of Folin-Ciocalteu reagent $(10 \%)$. After $5 \mathrm{~min}, 0.5 \mathrm{ml}$ of sodium carbonate $(7 \%)$ was added. The mixture was incubated in the dark for $60 \mathrm{~min}$ and the absorbance was read at $760 \mathrm{~nm}$ against a blank prepared with extraction solvent instead of the extract. Results were expressed as $\mathrm{mg}$ gallic acid equivalent per $100 \mathrm{ml}$ of oil.

Determination of flavonoids content: The method was based on the formation of flavonoid-aluminum complex that gives a yellowish coloration measurable at 420 $\mathrm{nm}$. Flavonoid concentration was determined according to the protocol proposed by Kumazawa et al. (2004). The results were expressed as milligrams of quercetin equivalent (QE) per $100 \mathrm{ml}$ of oil.

Determination of carotenoids content: Carotenoids content was determined according to Goula et al. (2017). Two grams of oil were weighed and dissolved in cyclohexane up to a final volume of $10 \mathrm{~mL}$. The absorbance of the obtained solution was measured at $470 \mathrm{~nm}$ and the results were expressed as milligrams of $\beta$-carotene equivalent ( $\beta$-CE) per $100 \mathrm{ml}$ of oil.

\section{Antioxidant activity}

DPPH radical scavenging activity: Free radical scavenging capacity was evaluated according to the method described by Molyneux (2004). The oil extract was appropriately diluted in methanol and was analyzed for their capacity to scavenge the DPPH radical at $515 \mathrm{~nm}$. The results were expressed as percentages following equation 4.

$$
R S A(\%)=\frac{A c-A s}{A c} \times 100
$$

where: RSA (\%), radical scavenging activity expressed in percentage; Ac, Absorbance of control; As, absorbance of sample.

Reducing power: Oil extract was mixed with Sodium phosphate buffer $(2.5 \mathrm{~mL}$, $0.2 \mathrm{M}, \mathrm{pH}$ 6.6) and Potassium ferricyanide $(2.5 \mathrm{ml}, 1 \%)$. The mixture was incubated at $50^{\circ} \mathrm{C}$ for $20 \mathrm{~min}$. An aliquot $(2.5 \mathrm{ml})$ of Trichloroacetic acid $(10 \%)$ 
was added to the mixture. The upper layer of solution $(2.5 \mathrm{ml})$ was mixed with distilled water $(2.5 \mathrm{ml})$ and $\mathrm{FeCl}_{3}(0.5 \mathrm{ml}, 0.1 \%)$, and the absorbance was measured at $700 \mathrm{~nm}$ in a spectrophotometer (Oyaizu, 1986). The results were expressed by absorbance values

\section{Antibacterial activity}

Four bacterial species were used, three with Gram-negative (Escherichia coli, Pseudomonas aeruginosa, and Proteus spp) and the other with Gram-positive (Staphylococcus aureus). They were obtained from the microbial collection of Microbiology Laboratory (Bejaia, Algeria). A loop full of each microorganism was suspended in $10 \mathrm{ml}$ of physiological water in a Roux bottle. Each was streaked on the appropriate culture medium and was incubated at $37^{\circ} \mathrm{C}$ for 24 hours. The suspensions were standardized for about $107 \mathrm{FCU} / \mathrm{ml}$ (Burt and Reinders, 2003).

\section{Antibiogram}

The antibiogram is a method that permits to put in evidence the antibacterial activity by measuring the diameter of the inhibition zone. The antibacterial activity was evaluated according to the method of Suay et al. (2000). For this purpose, the standardized inoculum of approximately $10^{7} \mathrm{CUF} / \mathrm{ml}$ was homogeneously distributed over the plates containing the Mueller-Hinton agar. The methanolic extract $(25 \mu \mathrm{l})$ was applied to the surface of the seeded assay plates, which were incubated at $37^{\circ} \mathrm{C}$. Inhibition zones around the application points were measured after 24 hours. The methanol was used as a negative control. The inhibitory effect of extract against each tested bacterium was determined by measuring the diameter of the inhibition zone (D) in millimeters. Antibacterial activity was expressed as following (Chiheb et al., 2009): $\mathrm{D}=0$, No activity (-): $\mathrm{D} \leq 10 \mathrm{~mm}$; low activity $(+): 10 \leq \mathrm{D}<16 \mathrm{~mm}$; Moderate activity $(++): 16 \leq \mathrm{D}<20 \mathrm{~mm}$; Good activity $(+++): \mathrm{D} \geq 20 \mathrm{~mm}$.

\section{Statistical analysis}

The results were analyzed using Statistica software (Statistica 5.5.fr.). One-way analysis of variance (ANOVA) test was used to determine the significant differences $(P<0.05)$ among the means.

\section{Results and discussion}

\section{Extraction yield of sesame oil}

Oil yield is an important quantitative parameter for a given oilseed, it indicates on richness in fat. Yield results obtained by the two extraction methods for unroasted and roasted sesame seeds are presented in Figure 1.

The oil percentage obtained was consistent with the reports from previous researchers, for example $(37.1 \%$ - 57.5\%) from Nigerian sesame seed, observed by Yahaya et al. (2014). Our results showed that the oil yield of the roasted sesame extracted with Soxhlet method was the highest, followed by unroasted sesame using Soxhlet and then by the roasted seeds extracted at low temperature. However, the unroasted sesame gave the lowest yield with only $32 \%$. It can be seen that 
Soxhlet method improved the yield of extraction. Up to 10 to $20 \%$ of oil was lost in by-product after cold extraction. The mechanical screw pressing is comparatively unproductive; leaving about 7.5-13.5\% remained oil in the cake (Asghar et al., 2014).

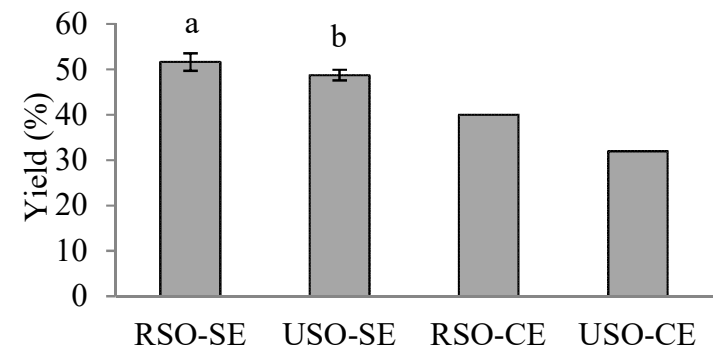

Figure 1. Extraction yields of sesame oils obtained by Soxhlet extraction and cold pressing. RSO - Roasted Sesame Oil; USO: Unroasted Sesame Oil; SE - Soxhlet Extraction; CE: Cold pressing Extraction. Results of oil yields with different letters are statistically different at $\mathrm{p}<0.05$ (Student test).

Using Soxhlet method and hexane as the extraction solvent, Corsoa et al. (2010) reported an oil yield of $43 \%$. Yields of oil extracted from roasted and unroasted sesame, using Soxhlet methods, were 43 and $45 \%$ respectively (Dim, 2013). The sesame oil level ranged from 41.6 to $62.5 \%$ (Asghar et al., 2014). The highest yield extraction of oil obtained using Soxhlet method can be due to the increased ability of the solvent to overcome forces that bind lipids within the sample matrix (Lumley and Colwell, 1991).

\section{Physicochemical parameters}

Moisture of sesame seeds and oil

The moisture of seeds and extracted oil was a critical factor for their conservation because the humidity was the origin of numerous chemical reactions and microbiological contaminations. Figure 2 illustrates moisture results of sesame seeds and oils.

The Student test indicated that moisture of unroasted sesame seeds was significantly $(p<0.05)$ higher than that of roasted one. For extracted oils, the moisture level of USO-CE was the highest, USO-SE and RSO-CE presents equal humidity $(\approx 0.9 \%$ ), while RSO-SE presented the lowest values.

According to the results, it can be seen that roasting decreased sesame seeds moisture and then, that of corresponding oil. During the roasting stapes, about $25 \%$ of moisture of seed was eliminated under high temperature $\left(180^{\circ} \mathrm{C}\right.$ during $\left.20 \mathrm{~min}\right)$. It showed also that oil extraction by Soxhlet had low moisture than the oil extracted by cold pressing. This can be explained by the evaporation of water during the extraction period.

Usually, once harvested, the seeds are cleaned and dried to about $8 \%$ moisture and then stored. Moisture quantities from 4.0 to $5.3 \%$ were indicated in commercially 
sesame seeds (Anilakumar et al., 2010). In general, the level of moisture of sesame seeds can vary from 3.9 to 6\% (Jeong et al., 2004; Elleuch et al., 2007; Nzikou et al., 2009; Gharby et al., 2015).

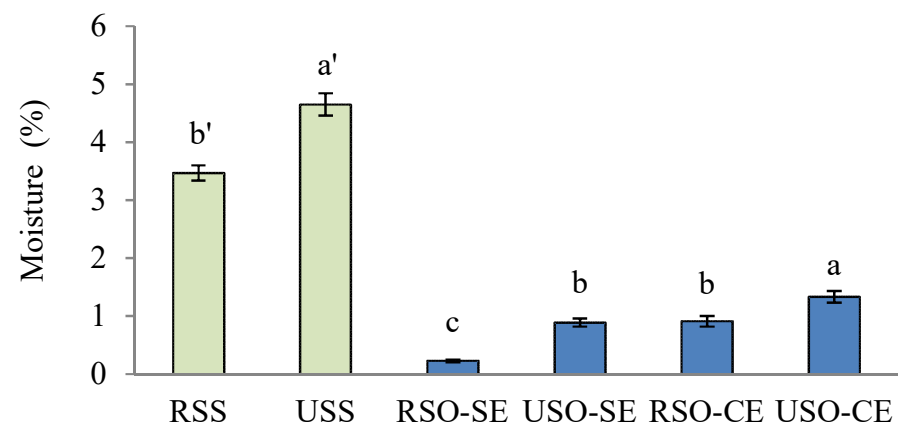

Figure 2. Moisture percentages of sesame seeds and oils obtained by Soxhlet extraction and cold pressing. RSS - Roasted Sesame Seeds; USS - Unroasted Sesame Seeds; RSO Roasted Sesame Oil; USO - Unroasted Sesame Oil; SE - Soxhlet Extraction; CE - Cold pressing Extraction. Results of sesame oil moistures with different letters are statistically different at $p<0.05$ (ANOVA-LSD test). Results of sesame seeds moistures with different letters are statistically different at $\mathrm{p}<0.05$ (Student test).

We found little data about oil moisture in scientific literature. Zhou et al. (2010) indicated that sesame oil has less than $0.2 \%$ water, similar to oil moisture obtained in the present study from roasted sesame extracted by Soxhled method. All other oils presented higher moisture percentages.

Moisture content has a significant influence on sesame seed oil yield. To increase oil yield, moisture content is reduced by increasing roasting duration and temperature (Asghar et al., 2014), which was confirmed by the results of this study. The roasting decreases the moisture level of sesame seeds resulting in improved oil yield.

Color

The results of color analysis of sesame oil as indicated in Table 1, illustrate that USO-CE had the most intense yellow and red colors, followed by RSO-SE and RSO-CE which were nearly similar for red color (about 2.7) and similar for yellow color (25). However, USO-SE was less intense for the two colors comparing to the other oils.

\section{Specific absorptivity}

The specific absorptivity of oil extracted by different methods (Soxhlet and cold pressing) from roasted and unroasted sesame seeds is reported in figure 3.

The highest specific absorptivity at $232 \mathrm{~nm}$ was obtained in RSO-SE followed by USO-SE, and then RSO-CE, while USO-CE expressed the lowest one. The specific absorptivity values at $270 \mathrm{~nm}$ of oils extracted by Soxhlet method were nearly equal. Cold pressing showed low specific absorptivity of oil; 0.26 and 0.14 were obtained for RSO-CE and USO-CE respectively. These results suggested that 
sesame seed oil stability to oxidation is relatively good, being due most probably to the presence of antioxidants.

Table 1. Color of sesame oils obtained in the study.

\begin{tabular}{ccc}
\hline \multirow{2}{*}{ Oil } & \multicolumn{2}{c}{ Color } \\
\cline { 2 - 3 } & Yellow & Red \\
\hline RSO-SE & 25 & 2.8 \\
USO-SE & 18 & 2.3 \\
RSO-CE & 25 & 2.6 \\
USO-CE & 46 & 4.3 \\
\hline
\end{tabular}

RSO - Roasted Sesame Oil; USO - Unroasted Sesame Oil; SE - Soxhlet Extraction; CE - Cold pressing Extraction.

Borchani et al. (2010) indicated specific absorptivities at 232 and $270 \mathrm{~nm}$ of 2.90 and 1.0 for oil extracted from sesame using maceration in hexane during one night. The authors indicated also that the storage of oil at $65^{\circ} \mathrm{C}$ increases the specific absorptivity.

The absorbance at $232 \mathrm{~nm}$ was related to the initial conjugated diene as well as to the primary compounds, such as hydroperoxides, formed by oxidation. The absorbance at $270 \mathrm{~nm}$ was related to the conjugated triene and to secondary compounds (ketones and aldehydes) formed by oxidation of primary products of oxidation (Elleuch et al., 2007; Borchani et al., 2010).

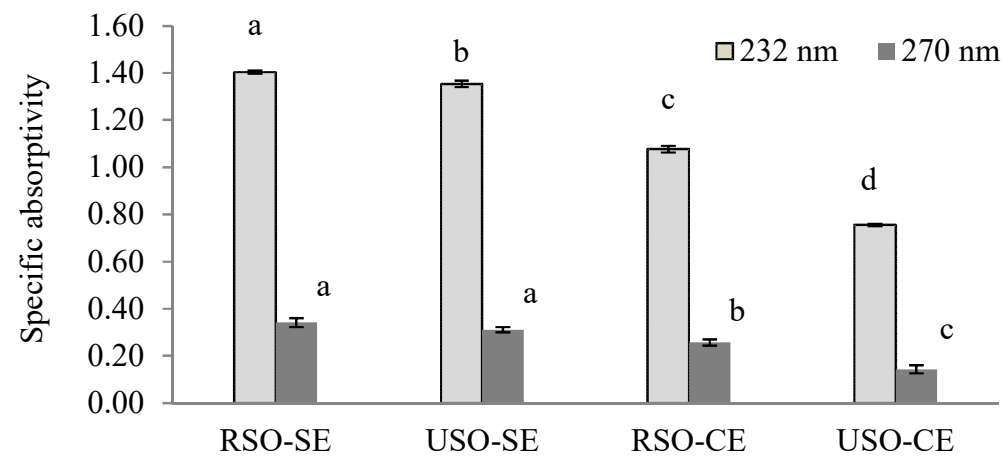

Figure 3. Specific absorptivity of sesame oils obtained by Soxhlet extraction and cold pressing. RSO - Roasted Sesame Oil; USO - Unroasted Sesame Oil; SE - Soxhlet Extraction; CE - Cold pressing Extraction. Results of specific absorptivity at 232 or $270 \mathrm{~nm}$ with different letters are statistically different at $\mathrm{p}<0.05$ (ANOVA-LSD test).

The high temperature of roasting and heating during Soxhlet extraction induced the increase of primary and secondary compounds of oxidation in oil which increased the specific absorptivity values at 232 and $270 \mathrm{~nm}$. 


\section{Refractive index}

Refractive index of different oil types varied from 1.4647 to 1.4653 indicating that treatment and extraction method didn't influence this parameter (Table 2).

Table 2. Refractive index of sesame oils obtained by Soxhlet extraction and cold pressing

\begin{tabular}{ccc}
\hline Oil type & Refractive index & Codex standard (2001) \\
\hline RSO-SE & $1.4647 \pm 0.0123^{\mathrm{a}}$ & \\
USO-SE & $1.4653 \pm 0.0074^{\mathrm{a}}$ & $1.469-1.479$ \\
RSO-CE & $1.4648 \pm 0.0045^{\mathrm{a}}$ & \\
USO-CE & $1.465 \pm 0.0112^{\mathrm{a}}$ & \\
\hline
\end{tabular}

RSO - Roasted Sesame Oil; USO - Unroasted Sesame Oil; SE - Soxhlet

Extraction; CE - Cold pressing Extraction. Results in each column with different letters are statistically different at $\mathrm{p}<0.05$ (ANOVA-LSD test).

The refractive index of analyzed sesame oils was similar to that reported by Elleuch et al. (2007) and Borchani et al. (2010), but relatively higher than that of other oils reported in scientific literature (date seed oil, virgin olive oil, Moringa oleifera seed oil) (Barminas et al., 1999; Lalas and Tsaknis, 2002; Besbes et al., 2004). This difference could be explained by a less intensified coloration.

\section{Chemical composition}

Table 3 regroups chemical quality parameters of sesame oils obtained in the present study.

Table 3. Chemical indication values of sesame oils obtained by Soxhlet extraction and cold pressing.

\begin{tabular}{lccc}
\hline & \multicolumn{3}{c}{ Index } \\
\cline { 2 - 4 } Oil type & $\begin{array}{c}\text { Peroxide value } \\
\text { (meq O } \mathbf{2} / \mathbf{k g ~ o i l})\end{array}$ & $\begin{array}{c}\text { Iodine value } \\
\text { (g of } \mathbf{~ I}_{\mathbf{2}} / \mathbf{1 0 0} \mathbf{g} \text { of oil) }\end{array}$ & $\begin{array}{c}\text { Saponification } \\
\text { value (mg KOH/g oil) }\end{array}$ \\
\hline RSO-SE & $8.2 \pm 0.123^{\mathrm{c}}$ & $107 \pm 6.42^{\mathrm{a}}$ & $189 \pm 9.45^{\mathrm{a}}$ \\
USO-SE & $8.7 \pm 0.087^{\mathrm{b}}$ & $108 \pm 3.24^{\mathrm{a}}$ & $188 \pm 1.28^{\mathrm{a}}$ \\
RSO-CE & $7.6 \pm 0.532^{\mathrm{c}}$ & $108 \pm 4.32^{\mathrm{a}}$ & $191 \pm 5.82^{\mathrm{a}}$ \\
USO-CE & $9.6 \pm 0.288^{\mathrm{a}}$ & $109 \pm 2.18^{\mathrm{a}}$ & $190 \pm 9.5^{\mathrm{a}}$ \\
Codex standard (2001) & $<10$ & $104-120$ & $186-195$ \\
\hline
\end{tabular}

RSO - Roasted Sesame Oil; USO - Unroasted Sesame Oil; SE - Soxhlet Extraction; CE - Cold pressing Extraction. Results in each column with different letters are statistically different at $\mathrm{p}<0.05$ (ANOVA-LSD test).

Peroxide level is an index of rancidity, thus the high peroxide value of oil indicates a poor resistance of the oil to peroxidation during storage (Asghar et al., 2014). The obtained results indicated that the oils extracted from roasted seeds presented peroxide values relatively lower than that of the oil obtained from unroasted sesame (Table 3). This can be explained by the low level of moisture in roasting sesame seeds. The presence of moisture can induce the peroxidation of sesame oil. 
This can be also due to the better liberation of antioxidants from roasted sesame seeds which protect the oil oxidation. The reduction in moisture content during roasting of sesame prevents molding and reduces staling and rancidity. Sesamol, an antioxidant, was detected only in roasted sesame oil (Fukuda et al., 1985; Junmin et al., 2019).

The high oxidative stability of sesame oil could be attributed to endogenous antioxidants (lignans particularly) together with tocopherols (Yoshida et al., 1995). The effectiveness of the lipid unsaponifiable matter in delaying oil deterioration has been demonstrated by other studies. A combination of the number of minor constituents such as tocopherol, sterol, and sesamol was reported to have a synergistic role in increasing the oxidation stability of oils (Mohamed and Awatiff, 1998).

The iodine value of the four sesame oils varied from 107 to $109 \mathrm{~g}$ of $\mathrm{I}_{2} / 100 \mathrm{~g}$. The roasting and the method of extraction did not influence this parameter (Table 3 ). The mean reported iodine values were ranged from 104 to 115 in oil from unroasted seeds and 106 to 111 in oil from roasted seeds. Values per country for unroasted seed oils were Burkina Faso (106-107), China (111-115), Egypt (104110), India (107-110), Japan (114), Mexico (110-112), Myanmar (112), and Thailand (112-114) (Crews et al., 2006). They confirmed that roasting of the seeds under the conditions used did not have a detectable effect on the iodine value. Seegeler (1983) indicated that iodine value of sesame oil can vary from 100 to 130 $\mathrm{g}$ of $\mathrm{I}_{2} / 100 \mathrm{~g}$ of oil. These results are further supported by the fatty acids composition.

Saponification is an indicator of average molecular weight and hence chain length. It has an inverse relationship with molecular weight of lipids (Dim, 2013). The saponification values of studied sesame oils were similar $(189-191 \mathrm{mg} \mathrm{KOH} / \mathrm{g}$ ) (Table 4). The Codex Standard (2001) indicated that saponification value of sesame oil has to be comprised between 186 and $195 \mathrm{mg} \mathrm{KOH} / \mathrm{g}$.

These results were in agreement with whose of Andraos et al. (1950), Borchani (2010), and Dim (2013) who reported 187-190 mg KOH /g saponification value of sesame oil. This last can vary from 185.8 to $199 \mathrm{mg} \mathrm{KOH} / \mathrm{g}$ (Seegeler, 1983).

\section{Fatty acids composition}

The gas chromatography (GC) analysis of oils fatty acids was indicated in Table 4 . The main fatty acid present in sesame oil was oleic acid (about $42.3 \%$ ) followed closely by linoleic acid (40.5-40.9\%). Sesame oil contains also high contents of palmitic and stearic acids with about 9.4 and $6.2 \%$ respectively. Only traces of linoleic and arachidic acids were detected, while eicosenoic acid was not determined in studied sesame oils.

The most abundant fatty acids present in sesame oil include oleic acid $(43 \%)$, linoleic acid (35\%), palmitic acid (11\%) and stearic acid (7\%) contributing toward $96 \%$ of total fatty acids (Elleuch et al., 2007). In general, sesame oil contains oleic (35.9-47\%), linoleic (35.6-47.6), palmitic (8.7-13.8\%), stearic (2.1-6.4\%), as well as arachidic acids $(0.1-0.7 \%)$ (Borchani et al., 2010). There was no clear difference 
in the fatty acid profile of oils from roasted and unroasted seeds. These results were in agreement with those of Crews et al. (2006)

Table 4. Fatty acids composition of sesame oils obtained by Soxhlet extraction and cold pressing.

\begin{tabular}{lccccccc}
\hline \multirow{2}{*}{ Oil type } & \multicolumn{7}{c}{ Fatty acid } \\
\cline { 2 - 8 } & C16:0 & C18:0 & C18:1 & C18:2 & C18:3 & C20:0 & C20:1 \\
\hline RSO-SE & 9.40 & 6.20 & 42.32 & 40.70 & nd & 0.67 & nd \\
USO-SE & 9.49 & 6.25 & 42.23 & 40.50 & 0.30 & 0.60 & nd \\
RSO-CE & 9.30 & 6.10 & 42.00 & 40.74 & 0.28 & 0.70 & nd \\
USO-CE & 9.54 & 6.27 & 42.59 & 40.91 & 0,20 & 0.68 & nd \\
\hline
\end{tabular}

nd - not detected; RSO - Roasted Sesame Oil; USO - Unroasted Sesame Oil; SE - Soxhlet Extraction; CE: Cold pressing Extraction.

\section{Total phenolic content}

Phenolic components serve as important antioxidants because of their proton and/or electron donating ability in order to form stable radical intermediates. Hence, they tend to prevent the oxidation of different biological molecules (Were et al., 2006).

Results found in this study indicate that oil obtained by cold pressing from roasted sesame seeds was the most concentrated in phenolic compounds, followed by RSO-SE, and finally by USO-SE and USO-CE with similar contents (Figure 4). The values obtained in this study were higher than those found by Borchani et al. (2010), who indicated that raw sesame oil extracted by maceration using hexane as solvent presented $14.21 \mathrm{mg} / \mathrm{kg}$ of polyphenols.

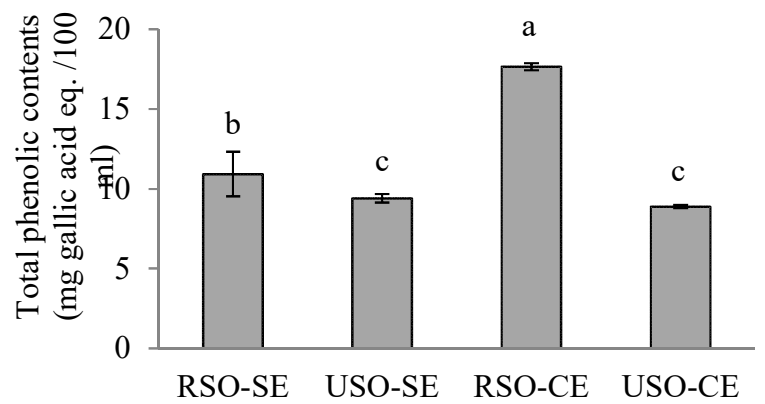

Figure 4. Total phenolic contents of sesame oils obtained by Soxhlet extraction and cold pressing. RSO / Roasted Sesame Oil; USO - Unroasted Sesame Oil; SE: Soxhlet Extraction; CE - Cold pressing Extraction. Results with different letters are statistically different at $\mathrm{p}<0.05$ (ANOVA-LSD test).

Several factors can influence phenolics content of sesame oil. Studies showed that extrinsic factors (as geographical and climatic factors), genetic factors, but also the maturation degree of plant and the length of storage influence on the content of antioxidant compounds (Williamson et al., 2008; Yasumoto, 2008). Sample 
treatment and extraction method can contribute to the variation of these compounds in sesame seed oils (Fukuda et al., 1994; Igual et al., 2012). Kim (2000) reported that the storage stability of unroasted sesame oil was low, but roasting of sesame seed at $170{ }^{\circ} \mathrm{C}$ or higher significantly increased the stability of sesame oil.

Sesame seeds contain several phenolic with different concentration including sesamol $\quad(0-11 \mathrm{mg} / 100 \mathrm{~g})$, pinoresinol $\quad(1.3-3.8 \mathrm{mg} / 100 \mathrm{~g})$, sesamolinol $(0.6-$ $1.9 \mathrm{mg} / 100 \mathrm{~g}$ ), and sesaminol $(0.3-1.4 \mathrm{mg} / 100 \mathrm{~g})$ (Lee et al., 2008). These compounds contribute mainly to the antioxidant activity of sesame oil (Fukuda and al., 1994). Jeong et al. (2004) indicated that roasting of sesame seeds cleaved and liberated phenolic compounds. Yoshida and Takagi (1997) also reported that sesamol content, a potent phenolic antioxidant, increased in the extracted oil as the roasting temperature of sesame seeds increased to $180^{\circ} \mathrm{C}$ or higher.

\section{Flavonoid content}

Flavonoid contents of studied sesame oils were illustrated in figure 5. RSO-CE was more concentrated in flavonoids; followed by RSO-SE and then by USO-SE and USO-CE with equal levels. A number of factors such as $\mathrm{pH}$, enzymes, light, and oxygen can affect the antioxidant activity of flavonoids. Similar to the biological activity, the stability of flavonoids is dependent on the structural features (Sarni et al., 1995).

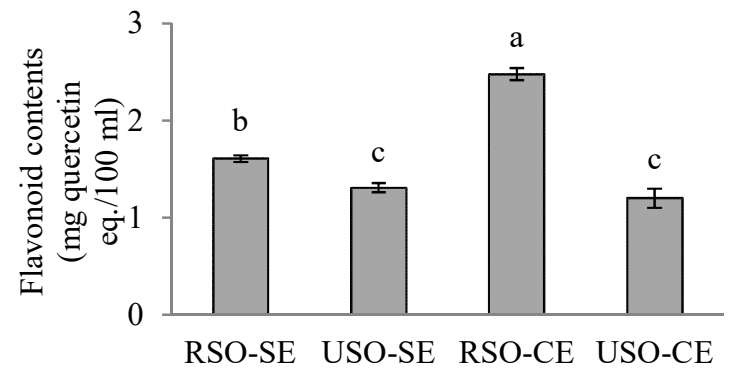

Figure 5. Flavonoid contents of sesame oils obtained by Soxhlet extraction and cold pressing. RSO - Roasted Sesame Oil; USO - Unroasted Sesame Oil; SE - Soxhlet Extraction; CE - Cold pressing Extraction. Results with different letters are statistically different at $\mathrm{p}<0.05$ (ANOVA-LSD test).

\section{Carotenoid content}

The results found in this study indicated that oil of unroasted sesame seeds extracted by Soxhlet was the most concentrated in carotenoids while the lowest content was observed for oil obtained from roasted sesame using cold pressing. All oils present statistically different content of carotenoids $(\mathrm{p}<0.05)$ (Figure 6).

It can be seen that roasting significantly affects carotenoids content. It can be remarked that unroasted seeds provide sesame oil more concentrated in carotenoids. This indicates that roasting negatively influences carotenoids amount. Carotenoids are susceptible to isomerization and oxidation during processing (heat treatment as roasting); the practical consequences are the loss of color and biologic activity and the formation of volatile compounds. The occurrence of carotenoids 
oxidation depends on the presence of oxygen, metals, enzymes, unsaturated lipids, prooxidants, and exposure to light (Rodriguez-Amaya, 2001).

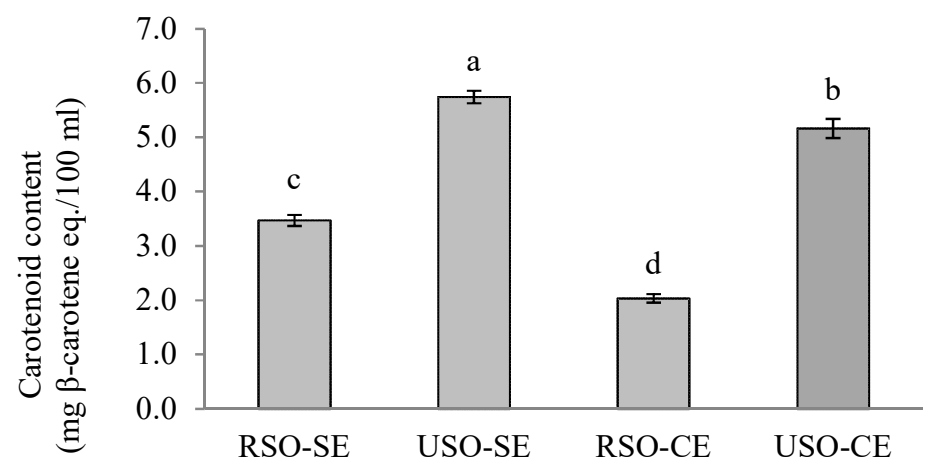

Figure 6. Carotenoid content of sesame oils obtained by Soxhlet extraction and cold pressing. RSO - Roasted Sesame Oil; USO - Unroasted Sesame Oil; SE - Soxhlet Extraction; CE - Cold pressing Extraction. Results with different letters are statistically different at $\mathrm{p}<0.05$ (ANOVA-LSD test).

\section{Antioxidant activity}

\section{DPPH scavenging activity}

The results of the antioxidant activity of oil samples, tested using DPPH scavenging, were presented in Figure 7.

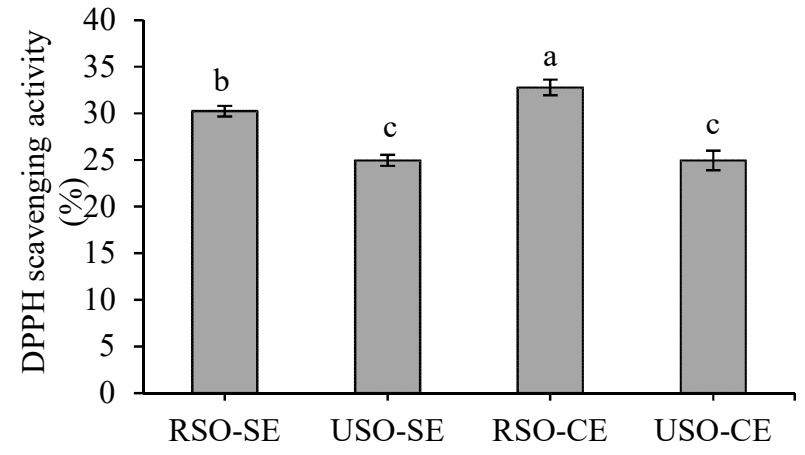

Figure 7. DPPH scavenging activity of sesame oils obtained by Soxhlet extraction and cold pressing. RSO - Roasted Sesame Oil; USO - Unroasted Sesame Oil; SE - Soxhlet Extraction; CE - Cold pressing Extraction. Results with different letters are statistically different at $\mathrm{p}<0.05$ (ANOVA-LSD test).

Statistical analysis indicated that the extract of RSO-CE was more efficient to scavenge DPPH radical, followed by the extract of RSO-SE; the extracts of USO$\mathrm{SE}$ and USO-CE expressed similar activities. Roasting enhances antioxidant capacity of the oil and this can be directly related to phenolic and flavonoid 
contents. Roasted sesame oil has been found to be more stable to oxidative deterioration than other vegetable oils. Abou-Gharbia et al. (1997) showed that autoxidation of commercial oils (soybean, rapeseed, safflower and corn oils) extracted at $60^{\circ} \mathrm{C}$ began after 5 to 20 days of incubation, while the oxidation of the roasted sesame oil started after 35 days and remained unaltered even after 50 days. It was found also that a large amount of sesamol was produced from sesamolin in oil of roasted seeds during the frying process which contributed mainly to the stability of this oil. This might explain the higher antioxidant power of roasted seeds oil compared to the commercial ones (Konsoula and LiakopoulouKyriakides, 2010).

\section{Reducing power}

The highest reducing power was presented by RSO-CE followed by RSO-SE, USO-SE, and USO-CE (Figure 8).

It can be observed, as in the case of DPPH scavenging activity, that the roasting process enhanced reducing power. The roasted sesame seed oil has a characteristic flavor and red-brown color, which are most probably caused by the Maillard reaction during roasting. It has been seen that the increase of roasting temperature leads to the raise of antioxidant activity and the intensification of the brown color by the formation of some browning products (Hassan, 2013). The strong antioxidative activity of the roasted oil might result from the synergistic effect of the combination of some compounds such as sesamol produced from sesamolin, tocopherol, sesamin, and roasted products like melanoidin (Fukuda et al., 1986; Fukuda et al., 1996; Koizumi et al., 1996). The oxidative stability of sesame oil is superior to that of other vegetable oils, even though it contains nearly $85 \%$ unsaturated fatty acids. Its remarkable stability is due also to the presence of a high quantity of endogenous antioxidants like some phenolic compounds (sesamin, sesamolin, and sesamol) and tocopherols (Sadeghi et al., 2009).

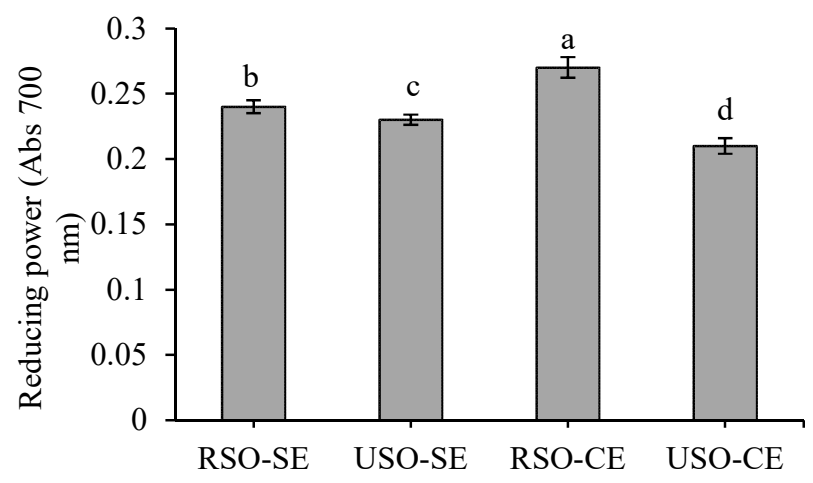

Figure 8. Reducing power of sesame oils obtained by Soxhlet extraction and cold pressing. RSO - Roasted Sesame Oil; USO - Unroasted Sesame Oil; SE - Soxhlet Extraction; CE Cold pressing Extraction. Results with different letters are statistically different at $\mathrm{p}<0.05$ (ANOVA-LSD test). 


\section{Antibacterial activity}

The results of antimicrobial activity of sesame oils were reported in table 5. These results showed that extracts obtained from sesame oils using cold pressing had more efficient antimicrobial activity against $E$. coli than those extracted by Soxhlet. However, the extract of roasted sesame oil obtained by cold pressing had the highest antibacterial activity toward Pseudomonas aeruginosa, followed by the roasted sesame oil extracted by Soxhlet. It is seen that roasting improves the antibacterial activity of sesame oil on Pseudomonas aeruginosa.

Table 5. Results of antimicrobial activity of sesame oils obtained in the present study.

\begin{tabular}{lcccc}
\hline \multirow{2}{*}{ Oil extract } & \multicolumn{4}{c}{ Bacterium } \\
\cline { 2 - 5 } & $\begin{array}{c}\text { Escherichia } \\
\text { coli }\end{array}$ & $\begin{array}{c}\text { Staphylococcus } \\
\text { aureus }\end{array}$ & $\begin{array}{c}\text { Pseudomonas } \\
\text { aeruginosa }\end{array}$ & Proteus sp. \\
\hline RSO-SE & $10 \mathrm{~mm}(+)$ & $(-)$ & $18 \mathrm{~mm}(++)$ & $(-)$ \\
USO-SE & $11 \mathrm{~mm}(+)$ & $(-)$ & $(-)$ & $(-)$ \\
RSO-CE & $14 \mathrm{~mm}(+)$ & $(-)$ & $26 \mathrm{~mm}(+++)$ & $(-)$ \\
USO-CE & $16 \mathrm{~mm}(++)$ & $(-)$ & $8 \mathrm{~mm}(-)$ & $(-)$ \\
\hline
\end{tabular}

RSO - Roasted Sesame Oil; USO - Unroasted Sesame Oil; SE - Soxhlet Extraction; CE - Cold pressing Extraction.

This antimicrobial activity could be due to some active ingredients of sesame, particularly lignans (such as sesaminol and its glucosides) which are recovered effectively during oil extraction process from sesame seeds (Rios and Recio, 2005). On the other hand, no extracts obtained from the four oils presented any antimicrobial activity toward Staphylococcus aureus and Proteus sp.

Antimicrobial activity can largely be affected according to the bacterial species, the strand type, and the gram as well as to antimicrobial agents (fatty acids, triglycerides, phenolics, volatile compounds, and the other compounds). Dilika et al. (2000) observed that oleic and linoleic acids expressed a good antibacterial activity. Quattara et al. (1997) and Zheng et al. (2005) showed that linoleic acid (C18:2) had a very strong antibacterial activity higher then oleic acid (C18:1). Antibacterial activity of oil can be also due to the presence of phenolic compounds (Karaosmanoglu et al., 2010). RSO-CE which presented the highest phenolic and flavonoid contents (17.64 and $2.48 \mathrm{mg} / 100 \mathrm{ml}$, respectively) had the best antimicrobial activity of all extracts. Xu and Lee (2001) showed that flavonoid components had significant antimicrobial activity. A small zone diameter of microorganism inhibition does not automatically indicate no activity of extract; this can be due to a small concentration of extract (Obeid et al., 2007).

\section{Conclusions}

In the present study, different parameters (physicochemical, antioxidant, and antibacterial activity) were analyzed in order to evaluate some quality parameters of sesame oil obtained from unroasted and roasted seeds, which was extracted by 
two methods: industrial process (cold pressing) and a laboratory one using Soxhlet extractor.

Roasting and Soxhlet extraction significantly ameliorated the extraction yield of sesame oils but induced a sensitive increase of specific absorbtivity. Extraction method (Soxhlet and cold pressing) and roasted/unroasted seeds oils presented close indexes values (peroxide, iodine, and saponification). Fatty acids composition of sesame oil revealed the dominance of oleic and linoleic acids. The highest phenolic and flavonoid contents, as well as antioxidant activity, were recorded for the oil sample obtained after roasting extracted with cold pressing. The antimicrobial activity showed that the most active oil was the RSO-CE followed by RSO-SE; this could be due to the roasting process, which enhances the liberation of phenolic compounds. Sesame oil presented antibacterial activity against Escherichia coli and Pseudomonas aeruginosa. All these characteristics lead to more diverse and novel applications of sesame oil in food, cosmetics, and pharmaceutical products. It is interesting to complete this study by testing sesame oil for its resistance to storage and heating.

\section{Acknowledgments}

The authors wish to express special thanks to Professor Abdelhak Mansouri for his help and his critical review of the manuscript.

\section{References}

Abou-Gharbia, H., Shahidi, F., Shehata, A., Youssef, M. 1997. Effects of processing onoxidative stability of sesame oil extracted from intact and dehulled seeds. Journal of the American Oil Chemists' Society, 74 (3), 215-221.

Andraos, V., Swift, C.E., Dollear, F. G. 1950. Sesame oil. I. Properties of solvent extracted sesame oil. Journal of the American Oil Chemists' Society, 27: 31-4.

Anilakumar, K.R., Pal, A., Khanum, F., Bawa, A.S. 2010. Nutritional, Medicinal and Industrial Uses of Sesame (Sesamum indicum L.) Seeds - An Overview. Agriculturae Conspectus Scientificus. 75 (4), 159-168.

AOAC. 1997. Official methods of Analysis 17th ed. Washington, DC: Association of official Agricultural

AOAC. 2005. Official methods of analysis (16th Ed.). Washington, DC: Association of Official Analytical Chemists.

AOAC. 2008. Official methods of analysis of the association of official analytical chemists.

Asghar, A., Majeed, M.N., Akhtar, M.N. 2014. A review on the utilization of sesame as functional food. International Journal of Food Sciences and Nutrition, 4(1), 21-34.

Barminas, J.T., James, M.K., Abubakar, U. M. 1999. Chemical composition of seeds and oil of xylopia aethiopica grown in Nigeria. Plant Foods for Human Nutrition, 53, $193-$ 198.

Besbes, S., Blecker, C., Deroanne, C., Lognay, G., Drira, N.E., Attia, H. 2004. Quality characteristics and oxidative stability of date seed oil during storage. Food Science and Technology International, 10, 333-338. 
Borchani, C., Besbes, S., Blecker, C.H., Attia, H. 2010. Chemical characteristics and oxidative stability of sesame seed, sesame paste, and olive oils. Journal of Agricultural Science and Technology, 12, 585-596.

Burt, S.A., Reinders, R.D. 2003. Antibacterial activity of selected plant essential oil Escherichia coli 0157: H7. Letters in Applied Microbiology, 36(3), 162-167.

Chiheb, I., Riadi, H., Martinez-Lopez, J., Dominguez, S.J.F., Gomez Vidal, J.A., Bouziane, H. Kadiri, M. 2009. Screening of antibacterial activity in marine green and brown macroalgae from the coast of Morocco. African Journal of Biotechnology, 8 (7), 12581262.

Codex Alimentarius. 2001. Named Vegetable Oils 8. Codex Standard. 210. 1-16.

Corsoa, M.P., Fagundes-Klena, M. R., Silva, E. A., Filhob, L. C., Santosc, J.N., Freitas, L.S. Darivac, C. 2010. Extraction of sesame seed (Sesamun indicum L.) oil using compressed propane and supercritical carbon dioxide. Journal of Supercritical Fluids, 52, 56-61.

Crews, C., Hough, P., Brereton, P., Godward, J., Lees M., Guiet S., Winkelmann, W. 2006. Quantitation of the main constituents of some authentic sesame seed oils of different origin. Journal of Agricultural and Food Chemistry, 54, 6266-6270.

Dilika, F., Bremner, P.D., Meyer, J.J.M. 2000. Antibacterial activity of linoleic and oleic acides isolated from Helichrysumpend uncuiatum: a plant used circumcision rites. Fititerapia, 71, 450-452.

Dim, P.E. 2013. Extraction and characterization of oil from sesame seed. Research Journal of Pharmaceutical, Biological and Chemical Sciences, 4 (2), 752.

Döker, O., Salgin, U.,Yildiz, N., Aydoğmus, M., Çalimli, A. 2010. Extraction of sesame seed oil using supercritical $\mathrm{CO}_{2}$ and mathematical modeling. Journal of Food Engineering, 97, 360-366.

El Hachimi, F., Elantari, A., Boujnah, M., Bendrisse, A. Alfaiz, C. 2015. Comparaison of oils seed and fatty acid content of various Moroccan populations of jujube, grenadier and prickly pear. Journal of Materials and Environmental Science, 6(5), 1488-1502.

Elleuch, M., Besbes, S., Roiseux, O., Blecker, C., Attia, H. 2007. Quality characteristics of sesame seeds and byproducts. Food Chemistry, 103, 641-650.

Fukuda, Y., Osawa, T., Namiki, M., Ozaki, T. 1985. Studies on antioxidative substances in sesame seed. Agricultural and Biological Chemistry, 49 (2), 301-306.

Fukuda, Y., Nagata, M., Osawa, T., Namiki, M. 1986. Chemical aspects of the antioxidative activity of roasted sesame seed oil and the effect of using the oil for frying. Agricultural and Biological Chemistry, 50, 857-962.

Fukuda, Y., Osawa, T., Kawakishi, S., Namiki, M. 1994. Chemistry of lignin antioxidants in sesame seed and oil, In: Food phytochemicals for cancer prevention II; Ho C. et al.; ACS symposium series; American Chemical Society: Washington, DC: 265-274.

Fukuda, Y., Koizumi, Y., Ito, R., Namiki, M. 1996. Synergistic action of the antioxidative components in roasted sesame seed oil. Nippon Shokukin Kagaku Kogaku Kaishi, 43 (12), 1272-1277.

Gharby, S., Harbar, H., Bouzoubaa, Z., Asdadi, A., El Yadini, A., Charrouf, Z. 2015. Chemical characterization and oxidative stability of seeds and oil of sesame grown in Morocco. Journal of the Saudi Society of Agricultural Sciences, 16(2), 105-111. 
Goula, A.M., Ververi, M., Adamopoulou, A., Kaderides, K. 2017. Green ultrasoundassisted extraction of carotenoids from pomegranate wastes using vegetable oils. Ultrasound. Sonochemistry, 34, 821-830.

Gutfinger, T. 1981. Polyphenols in olive virgin oils. Journal of the American Oil Chemists' Society, 58, 966-968.

Halliwell, B. 1997. Antioxidants and human diseases: a general introduction. Nutrition Reviews, 55(1), S44-S49.

Hassan, M.A.M. 2013. Studies on Egyptian sesame seeds (Sesamum indicum L.) and its products. 2. Effect of roasting conditions on peroxide value, free acidity, iodine value and antioxidant activity of sesame seeds (Sesamum indicum L.). World Journal of Dairy and Food Sciences, 8(1), 11-17.

Ichihara, K., Shibahara, A., Yamamoto, K., Nakayama, T. 1996. An improved method for rapid analysis of the fatty acids of glycerolipids. Lipids, 31, 535-539.

Igual, M., García-Martínez, E., Camacho, M.M., Martínez-Navarrete, N. 2013. Jam processing and storage effects on $\beta$-carotene and flavonoids content in grape fruit. Journal of Funtional Foods, 5(2), 736-744.

Janat, B., Oveysi, M., Sadeghi, N., Haji, M.M., Behzad, M., Choupankari, E., Behfar, A. 2010. Effects of roasting temperature and time on healthy nutraceuticals of antioxidants and total phenolic content in Iranian sesame seeds (Sesamum indicum L.). Iranian Journal of Environmental Health Science and Engineering, 7(1), 97-102.

Jeong, S.M., Kim, S. Y., Kim, D. R., Nam, K. C., Ahn, D.U., Lee, S. C. 2004. Effect of seed roasting conditions on the antioxidant activity of defatted sesame meal extracts. Food Chemistry and Toxicology, 69, 5.

Junmin, J., Yulan, L., Longkai, SH., Nannan, W., Xuede, W. 2019. Effect of roasting treatment on the chemical composition of sesame oil. LWT-Food Science and Technology, 101, 191-200.

Junpeng, Y., Zhang, Q., Xin, L., Xinsheng, W., Bing, L., Wenxue, ZH. 2019. Steam explosion technology based for oil extraction from sesame (Sesamum indium L.) seed. Journal of the Saudi Society of Agricultural Sciences, 18, 1-6.

Kamal-Eldin, A., Appelqvist, L. 1994. Variation in fatty acid composition of the different acyl lipids in seed oils four sesamum species. Journal of the American Oil Chemists' Society, 71, 135-139.

Kandji, N.A. 2001. Study of the chemical composition and the quality of artisanal vegetables oils consumed in Senegal. University Cheikh Anta, DIOP, DAKAR, 99 p.

Karaosmanoglu, H., Soyer, F., Ozen, B., Tokatli, F. 2010. Antimicrobial and antioxidant activity of Turkish extra virgin olive oils. Journal agricultural and Food Chemistry, 58, 8238-8245.

Kaufman, H.P. 1958. Analyse der fette und fetteprodukte. 571 Springer Verlag-Berlin.

Konsoula, Z., Liakopoulou-Kyriakides, M. 2010. Effect of endogenous antioxidants of sesame seeds and sesame oil to the thermal stability of edible vegetable oils. LWT-Food Science and Techology, 43, 1379-1386.

Kim, H.W. 2000. Studies on the antioxidative compounds of sesame oils with roasting temperature. Korean Journal of Food Science and Technology, 32, 246-51.

Koizumi, Y., Fukuda, Y., Namiki, M. 1996. Effect of roasting conditions on antioxidative activity of roasted sesame seed oil. I. Marked antioxidative activity of seed oils 
developed by roasting of sesame seeds. Nippon Shokuhin Kagaku Kogaku Kaishi, 43, 689-694.

Kumazawa, S., Hamasaka, T., Nakayama, T. 2004. Antioxydant activity of propolis of various geographic origins. Food Chemistry, 84, 329-339.

Lalas, S., Tsaknis, J. 2002. Characterization of Moringa oleifera seed oil variety "Periyakulam 1". Journal of Food Composition and Analysis, 15, 65-77.

Lee, J.H., Lee, Y.S., Choe, E. 2008. Effects of sesamol, sesamine and sesamolin extracted from roasted sesame oil on the thermal oxidation of methyl linoleate. LWT-Food Science and Technology, 41, 1871-1875.

Lee, S.W., Jeung, M.K., Park, M.H., Lee, S.Y., Lee, J. 2010. Effects of roasting conditions of sesame seeds on the oxidative stability of pressed oil during thermal oxidation. Food chemistry, 118(3), 681-685.

Lumley, I.D., Colwell, R.K. 1991. Fats from fatty foods and determination of fat content. In: Analysis of fats and fatty foods. Rossell, J.B. and J.L.R. Pritchard, (Eds.). pp: 238247.

Lyon, C.K. 1972. Sesame, current knowledge of composition and use. Journal of the American Oil Chemists' Society, 49(4), 245-249.

Mohamed, H.M.A., Awatiff, I.I. 1998. The use of sesame unsaponifiable matter as a natural antioxidant. Food Chemistry, 62, 269-276.

Molyneux, P. 2004. The use of the stable free radical diphenylpicrylhydrazyl (DPPH) for estimating antioxidant activity. Journal of Science and Technology, 26, 211-219.

Nayar, N.M., Mehra, K.L. 1995. Sesame: its uses, botany, cytogenetics and origin. In: Evolution of crop plants, $2^{\text {nd }}$ Edition, Smatt J. and Simmond, N.M., Edition Longman, N.W., London, 404-407.

Mordret, F., Coustille, J.L., Lacoste, F. 1997. Physico-chemical methods of analysis of the olive oils. $O C L, 4(5), 364-368$.

NF T 60-234. 1977. Animal and vegetable fats and oils-Analysis of the methyl esters of fatty acids by gas phase chromatography.

NF EN ISO 659. 2009. Animal and vegetable fats and oils-Oil seeds determination of oil content (reference method).

Nzikou, J.M., Matos L., Bouanga-Kalou, G., Ndangui, C.B., Pambou-Tobi, N.P.G., Kimbonguila, A., Silou, T., Linder, M., Desobry, S. 2009. Chemical composition on the seeds and oil of sesame (Sesamum indicum L.) grown in Congo-Brazzaville. Advance Journal of Food Science and Technology, 1(1), 6-11.

Obeid, H.K., Bedood, J.D.R., Prenzer, P.D., Robards, K. 2007. Chemical screening of olive biophenol extracts by hyphenated liquid chromatography. Analytica Acta, 603: 176-189.

Oyaizu, M. 1986. Studies on products of browning reaction: antioxidative activities of browning reaction prepared from glucosamine. Japanese Journal of Nutrition, 44, 307315.

Quattara, B., Simard, R.E., Holley, R.A., Piette, G.J., Bégin, V. 1997. Antibacterial activity of selected fatty acids and essential oils against six meat spoilage organisms. International Journal of Food Microbiology, 37, 155-162.

Rajaei, A., Barzegar, M., Sahari, M.A. 2008. Comparaison of antioxidative effect of tea and sesame seed oils extracted by different methods. Journal of Agriculture, Science and Technology, 10, 345-350. 
Rios, J.L., Recio, M.C. 2005. Medicinal plants and antimicrobial activity. Journal of Ethnopharmacology, 100, 80-84.

Rodriguez-Amaya, D.B. 2001. A guide to carotenoid analysis in foods. International Life Sciences Institute Press, 1-71.

Sadeghi, N., Oveysi, M.R., Hajimahmoodi, M., Jannat, B., Mazaheri, M., Mansouri, S., 2009. The content of sesamol in Iranian sesame seeds. Iranian Journal of Pharmaceutical Research, 8, 101-105.

Sarni, P., Fulcrand, H., Souillol, V., Souquet, J., Cheynier, V. 1995. Mechanism of anthocyanin degradation in grape must-like model solutions. Journal of the Science of Food and Agriculture. 69, 385-391.

Seegeler, C.J.P. 1983. Oil plants in Ethiopia, their taxonomy and agricultural significance. Agricultural Research Report, 921, 248-280.

Singleton, V.L., Rossi, J.A. 1965. Colorimetry of total phenolics with phosphomolybdicphosphotungstic acid reagents. American Journal of Enology and Viticulture, 16, 144 158.

Suay, I., Arenal, F., Asensio, F.J., Basilio, A., Cabello, M.A., Diez, M.A., Garcia, J.B., Gonzalezdel, V.A., Gorrochategui, J., Hernandez, P., Pelaez, F., Vicente, M.F. 2000. Screening of basidiomycetes for antibacterial activities. Antonie van Leeuwenhoek, 78, 129-139.

Sudke, S.G, Sakarkar, D.M. 2013. An extensive insight on physic-chemical characterization of hot-melt coating excipients. International Journal of PharmTech Research, 5(3), 879-893.

Warra, A.A. 2011. Sesame (Sesamum Indicum L.) seed oil methods of extraction and its prospects in cosmetic industry: A Review. Bayero Journal of Pure and Applied Sciences, 4(2), 164-168.

Were, B.A., Onkware, A.O., Gudu, S., Welander, M., Carlsson, A.S. 2006. Seed oil content and fatty acid composition in East African sesame (Sesamum indicum L.) accessions evaluated over 3 years. Field Crops Research, 97, 254-260.

Williamson, K.S., Morris, J. B., Pye, Q.N., Icamat, C.D., Hensley, K. 2008. A survey of sesamin and composition of tocopherol variability from seeds of eleven diverse sesame (Sesamum indicum L.) genotypes using HPLC-PAD-ECD. Phytochemical Analysis, 19(4), 311-22.

Xu, H.X., Lee, S.F. 2001. Activity of plant flavonoids against antibiotic-resistant bacteria. PhytotherapyResearch, 15, 39-43.

Yahaya, S.A., Falusi, O.A.Y., Muhammad, L.M., Abdulkarim, B.M. (2014). Evaluation of seed-oil, and yield parameters of some Nigerian sesame (Sesamum indicum). International journal of agriculture and crop sciences, 7(10), 661-664.

Yasumoto, S. 2008. Factors affecting variation in the sesamin and sesamolin contents of sesame (Sesamum indicum L.) seeds, breeding of a new lignin-rich sesame cultivar and evaluation of the functionality of the seeds in fatty acid metabolism. Bulletin of the National Institute of Agricultural, 9, 27-61.

Yoshida, H., Shigezaki, J., Takagi, S., Kajimoto, G. 1995. Variations in the composition of various acyl lipids, tocopherols and lignans in sesame seed oils roasted in a microwave oven. Journal of the Science of Food and Agriculture, 68, 407-415. 
Yoshida, H., Takagi, S. 1997. Effects of seed roasting temperature and time on the quality characteristics of sesame (Sesamum indicum) oil. Journal of the Science of Food and Agricultural, 75, 19-26.

Zheng, C.J., Yooaj, S., Leeb, T.G., Choc, H.Y., Kimd, Y.H., Kima, W.G. 2005. Fatty acid synthesis is a target for antibacterial activity of unsaturated fatty acids. FEBS Lettres, 579, 5157-5162.

Zhou, J.C., Feng,D.W., Zheng, G.S. 2010. Extraction of sesamin from sesame oil using macroporous resin. Journal of Food Engineering, 100, 289-293. 